\title{
UNIVERSAL MODEL FORMS FOR PREDICTING THE DYNAMIC PROPERTIES OF GRANULAR SOILS
}

\author{
Meysam BAYAT
}

Department of Civil Engineering, Najafabad Branch, Islamic Azad University, Najafabad, Iran

*Corresponding author's e-mail: bayat.m@pci.iaun.ac.ir

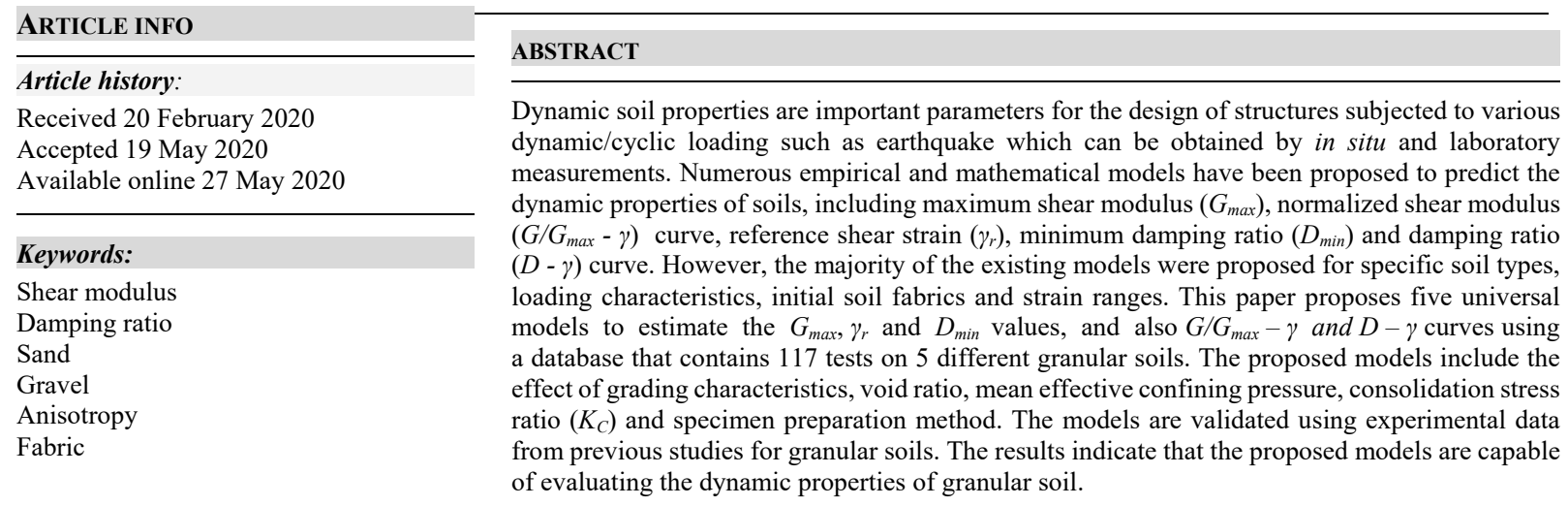

\section{INTRODUCTION}

It is generally recognized that local soil properties affect the ground response when seismic waves propagate through a soil profile. Advances in earthquake ground response analyses which includes predicting the dynamic response of a structure at the geotechnical site have greatly surpassed the knowledge of the basic dynamic soil properties. Some of the most important ground motion parameters are amplitude of motion, frequency content and duration. These parameters are primarily affected by some factors i.e. source effects or the characteristics of the earthquake, path effects, and site effects. A proper understanding of the site response is a key consideration in the solution of earthquake engineering problems. In this regard, laboratory element testing that can mimic field loading conditions plays an important role in understanding dynamic behaviour of soil layers or site effect. The shear modulus $(G)$ and damping ratio $(D)$ are two variable properties of soils are important straindependent parameters in estimation of seismic response of a site. Measurements of the shear modulus and damping ratio can be obtained from either laboratory or field tests. Shear modulus at small strains where soils exhibit linear elastic behavior is referred to as smallstrain shear modulus, $G_{\max }$ or $G_{o}$ and material damping ratio is referred to as small-strain or minimum material damping ratio, $D_{\min }$. The nonlinearity in the stressstrain relationship results in a decrease in the shear modulus with increasing shear strain amplitude and an increase in energy dissipation and therefore an increase in material damping ratio.

The effect of mean effective confining pressure and void ratio on $G_{\max }$ of granular soil has been documented by various investigators (e.g. Hardin and Drnevich, 1972; Stokoe et al., 1999; Gu et al., 2015; Payan et al., 2016). The results indicate that $G_{\max }$ increases with increasing mean effective confining pressure and decreases with increasing void ratio. The previous study suggested that shear strain level, void ratio, mean effective confining pressure, grain size distribution characteristics, drainage conditions, stress and fabric anisotropies, shape of particles and loading frequency are important effective parameters on the dynamic properties of granular soils (e.g. Wichtmann et al., 2015; Payan et al., 2016; Chen et al., 2018; Bayat and Ghalandarzadeh, 2018 and 2019). Other parameters have less important effect.

So far, various analytical and empirical models to predict the dynamic properties of granular soils have been proposed (Hardin and Drnevich, 1972; Darendeli 2001; Zhang et al., 2005; Amir-Faryar et al., 2017). The hyperbolic model proposed by Hardin and Drnevich (1972) has been widely used to describe nonlinear soil behavior under dynamic loading. In the proposed hyperbolic model, only one curve-fitting variable (i.e. reference shear strain, $\gamma_{r}$ ) is involved which results in the model having a poor fit to test data. Using modified hyperbolic models which include a curvature coefficient, such as the model suggested by 
Stokoe et al. (1999), Darendeli (2001) and Zhang et al. (2005) results in significantly improved fits to the data. However, few studies have been conducted on the parameters of the modified hyperbolic models. Darendeli (2001) introduced a reference strain which was different from Hardin and Drnevich's reference strain at which the shear modulus reduces to half of its maximum value. This modified hyperbolic model was later verified for sandy and gravelly soils by Menq (2003). The results indicate that $G / G_{\max }-\gamma$ curve of granular soils is a function of uniformity coefficient $\left(C_{u}\right)$ and mean effective confining pressure $\left(\sigma_{\mathrm{m}}^{\prime}\right)$.

Recent studies indicate that increasing the $C_{u}$ of granular soils leads to more nonlinear shape of the $G / G_{\max }-\gamma$ curves (e.g., Menq, 2003; Anastasiadis et al., 2011; Wichtmann et al., 2011; Senetakis, 2011). However, this trend was not observed in some of previous studies (e.g., Seed and Idriss, 1970; Seed et al., 1986; Rollins et al., 1998). Anastasiadis et al. (2011) and Senetakis (2011) indicated that the poorly graded sands generally have a more linear behavior in comparison to the poorly graded gravels. The results also indicated that the mean grain size $\left(d_{50}\right)$ affects the $G / G_{\max }-\gamma$ and $D-\gamma$ curves. However, this trend was not observed by Menq (2003) and Wichtmann et al. (2011). Previous studies indicated that the increase of $\sigma_{\mathrm{m}}^{\prime}$ results in more linear behaviour (Menq, 2003;

Kokusho et al., 2004; Xenaki and Athanasopoulos 2008; Anastasiadis et al., 2011; Jafarian et al., 2014; Araei and Ghodrati, 2017). Also, previous studies showed that with the increase of mean effective confining pressure and relative density, damping ratio tends to decrease for all shear strain levels (e.g. Chen et al., 2018; Bayat and Ghalandarzadeh, 2018). Although many studies have been done on the dynamic properties of granular soils over the past 50 years, only a few studies (e.g., Payan et al., 2016; Zhou et al., 2017; Chen et al., 2018; Bayat and Ghalandarzadeh, 2019) have considered the effect of inherent and induced anisotropies on the dynamic properties of granular soils. Zhou et al. (2017) and Bayat and Ghalandarzadeh (2020) studied the effects of initial static shear stress on the dynamic properties of granular materials. The results show that the values of $G / G_{\max }$ increase with an increasing initial static stress. Bayat and Ghalandarzadeh (2019) studied the effects of initial fabric on the dynamic properties of granular soils. Based on the results, it can be concluded that the effect of initial fabric on $D$ is more pronounced than on $G / G_{\max }$ and also this effect seems to be independent of soil type.

The current study presents the results of a series of cyclic triaxial, resonant column and bender element tests for granular materials in a wide shear strain range from the orders of $10^{-6}-10^{-2}$, and the effects of mean confining pressure, void ratio, grading characteristics and inherent and induced anisotropies on the dynamic properties are evaluated. Modified models are developed to accurately characterize the $G_{\max }, \gamma_{r}, D_{\min }$ and also $G / G_{\max }-\gamma$ and $D-\gamma$ curves. Using the experimental data, the applicability of the models is assessed in the estimation of the dynamic properties of granular soils.

\section{DATABASE}

The existing laboratory data used in the current study are compiled from the author's published works. Table 1 summarizes the sources of data used in this study that include bender element, resonant column and cyclic triaxial tests. In this paper, the shear modulus and damping ratio of specimens at the medium to large shear strain range (shear strain ranging from 10-4 and 10-2) were extracted from the results of cyclic triaxial testing and the results of resonant column test were used to derive the dynamic properties at small to medium shear strain amplitudes (approximately between 10-6 and 10-4). Bender element was used to monitor the small strain shear modulus at very small strain amplitudes $(\gamma \leq 10-5)$. Test apparatus, materials properties and testing procedure are presented in summary in the following section. More details can be found in Bayat and Ghalandarzadeh (2018, 2019 and 2020).

\section{TEST APPARATUS, MATERIALS AND TESTING PROCEDURE}

\subsection{TEST APPARATUS}

As mentioned in the previous section, bender element, resonant column and cyclic triaxial

Table 1 Summary of the sources of data used in the current study.

\begin{tabular}{|c|c|c|c|c|c|c|c|}
\hline Test Group & Variables & $\sigma_{\mathrm{m}}^{\prime}(\mathbf{k P a})$ & $\mathrm{K}=\frac{\sigma_{1}^{\prime}}{\sigma_{\mathrm{a}}^{\prime}}$ & Dr (\%) & $\begin{array}{l}\text { Depositional } \\
\text { method }\end{array}$ & $\begin{array}{c}\text { No. of } \\
\text { tests }\end{array}$ & References \\
\hline Group-1 & $\begin{array}{l}\sigma_{\mathrm{m}}^{\prime}, \text { Dr and Grading } \\
\text { characteristics }\end{array}$ & $\begin{array}{l}100,300 \\
\text { and } 600\end{array}$ & 1 & $\begin{array}{l}10,30 \\
\text { and } 60\end{array}$ & WT & 45 & $\begin{array}{c}\text { Bayat and } \\
\text { Ghalandarzdeh } \\
(2018) \\
\end{array}$ \\
\hline Group-2 & $\begin{array}{l}\sigma_{\mathrm{m}}^{\prime}, \text { Dr, Grading } \\
\text { characteristics and } \mathrm{K}\end{array}$ & $\begin{array}{l}267,280, \\
300,333 \\
\text { and } 400\end{array}$ & $\begin{array}{c}0.5,0.75 \\
1,1.25 \\
\text { and } 1.5\end{array}$ & $\begin{array}{l}10,30 \\
\text { and } 60\end{array}$ & WT & 51 & $\begin{array}{c}\text { Bayat and } \\
\text { Ghalandarzdeh } \\
(2020)\end{array}$ \\
\hline Group-3 & $\begin{array}{l}\sigma_{\mathrm{m}}^{\prime}, \text { Dr, grading } \\
\text { characteristics and } \\
\text { Depositional method }\end{array}$ & $\begin{array}{l}100,300 \\
\text { and } 600\end{array}$ & 1 & $\begin{array}{l}10 \text { and } \\
60\end{array}$ & $\begin{array}{l}\text { WT, AP } \\
\text { and WP }\end{array}$ & 21 & $\begin{array}{c}\text { Bayat and } \\
\text { Ghalandarzdeh } \\
\text { (2019) }\end{array}$ \\
\hline
\end{tabular}




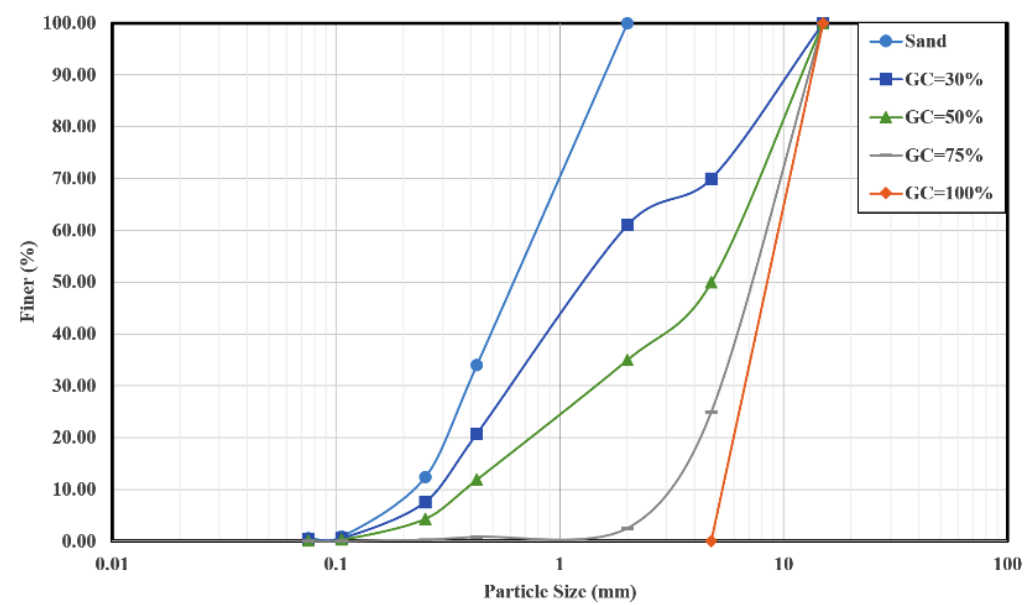

Fig. 1 Grain size distribution curves of the granular soil mixtures.

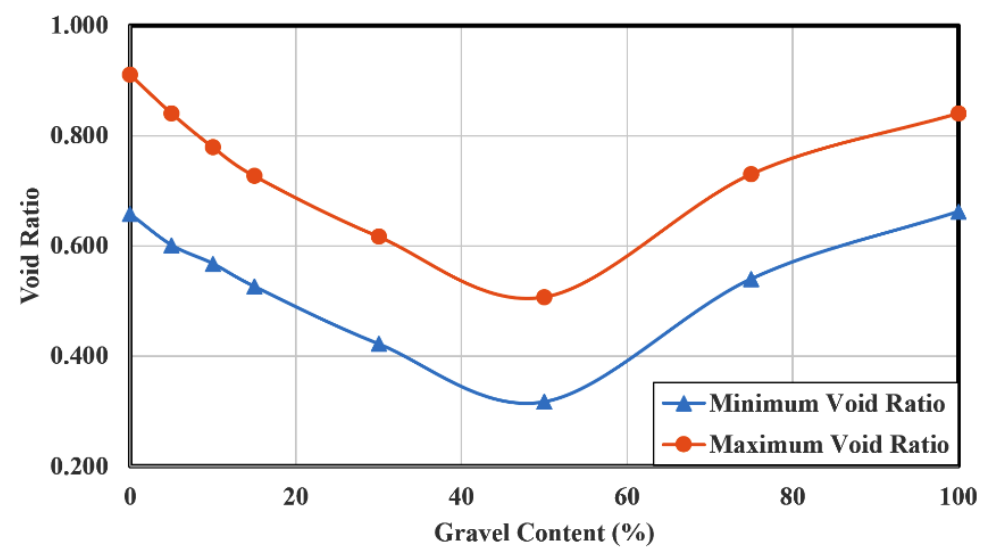

Fig. 2 Maximum and minimum composite void ratios versus gravel content.

apparatuses were used to measure the shear modulus and damping ratio of granular soils. The cyclic triaxial tests were carried out according to the specifications of the ASTM D3999 (2013) to drive the shear modulus and damping ratio at medium to large shear strain amplitudes. In cyclic triaxial testing, a slow axial loading was applied at the top of the specimen. Axial strain was measured by two LVDTs (linear variable differential transducers) placed at opposite on the triaxial specimen. Based on the stress and displacement at the top of the specimen, hysteresis loops are generated. The shear modulus for each cycle of loading is evaluated by calculating the slope of the line that connects the end points of the hysteresis loop. Damping ratio is evaluated by calculating the ratio of the area within the hysteresis loop and the maximum potential energy stored in each cycle of motion as represented by the triangular area. A pair of bender elements (i.e. a transmitter and a receiver) was implemented in the triaxial cell to determine the shear wave velocity $\left(V_{S}\right)$. The first major deflection of the received signal is utilized to determine the shear wave arrival time. The $V_{S}$ is measured and the very small shear strain modulus, $G_{\max }$, is calculated $\left(\mathrm{G}_{\max }=\rho . \mathrm{V}_{\mathrm{S}}^{2}\right)$. The shear modulus and damping ratio of the specimens at small shear strains was measured using a free-free resonant column apparatus. The freevibration decay (FVD) method was used for damping derivation. The bender element, resonant column and cyclic triaxial tests were combined in order to determine the normalized shear modulus degradation and damping curves of the granular specimens.

\subsection{MATERIAL AND TESTING PROCEDURE}

Five gradations of granular material were used to study the influence of grading characteristics, relative density, mean effective stress, inherent and induced anisotropies on the dynamic properties. The pure sand and gravel were clean, uniformly-graded that was classified as $S P$ and $G P$ according to the unified soil classification system (USCS), respectively. Each subgroup of the materials was denoted by the values of the gravel content $(G C)$. For example, the gravel content of GC-30 is $30 \%$ by weight. The grain size distribution curves of the materials with varying gravel contents are shown in Figure 1. Table 2 shows grading characteristics of the materials. The maximum and minimum void ratios $\left(e_{\max }\right.$ and $\left.e_{\min }\right)$ versus gravel content are presented in Figure 2. Table 1 summarizes the number of tests carried out on reconstituted specimens with a diameter of $100 \mathrm{~mm}$ and a height/diameter ratio equal to 2 which were prepared 
Table 2 Grading characteristics of five soil subgroups.

\begin{tabular}{lccc}
\hline Soil subgroup & $\boldsymbol{d}_{\boldsymbol{5 0}}(\mathbf{m m})$ & $\boldsymbol{C}_{\boldsymbol{u}}$ & $\boldsymbol{C}_{\boldsymbol{c}}$ \\
\hline GC-0 & 0.61 & 3.59 & 0.88 \\
GC-30 & 1.15 & 7.02 & 1.15 \\
GC-50 & 4.75 & 15.39 & 4.75 \\
GC-75 & 7.07 & 2.67 & 7.07 \\
GC-100 & 8.30 & 1.80 & 8.30 \\
\hline
\end{tabular}
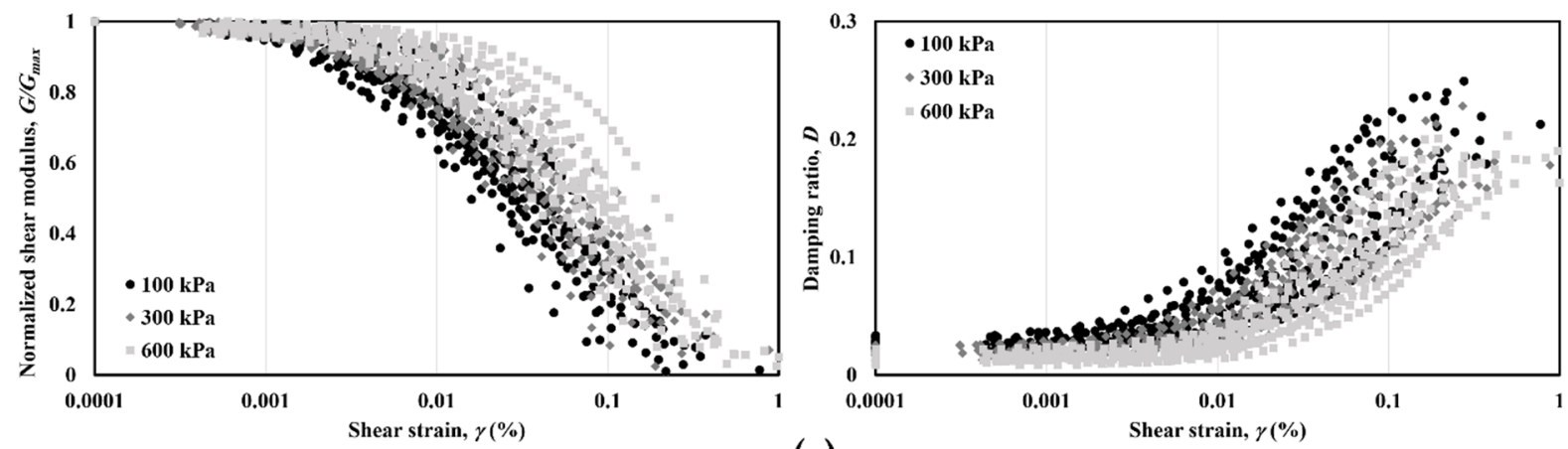

(a)
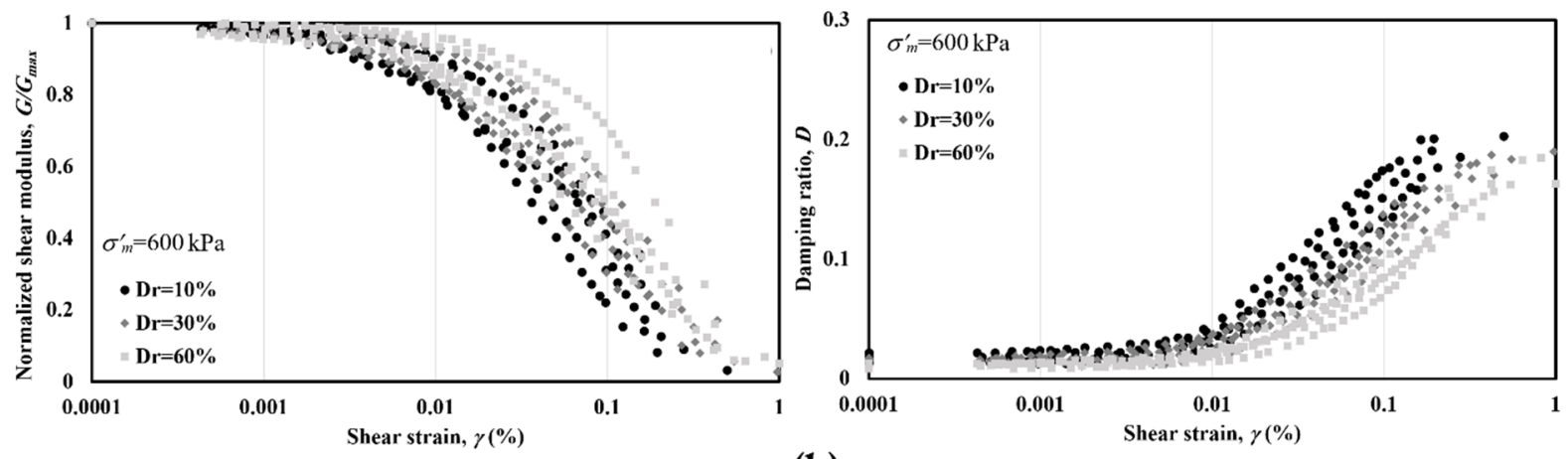

(b)

Fig. 3 Variation of $G / G_{\max }$ and $D$ as a function of $\gamma$ in terms of (a) mean effective confining pressure (b) relative density.

by wet tamping (WT), water pluviation (WP) or air pluviation (AP). More details can be found in Bayat and Ghalandarzadeh (2018, 2019 and 2020).

\section{TESTS RESULTS AND DISCUSSION}

The dynamic properties of the all subgroups of materials (GC - 0, GC - 30, GC - 50, GC - 75 and GC - 100) under isotropic or anisotropic loading conditions were determined from bender element, resonant column and cyclic triaxial testing. Based on the results, the effects of relative density, mean effective stress, grading characteristics, induced anisotropy and deposition method on the dynamic properties were assessed. Note that the tests results presented in section 4 are related to the results of the current study and the author's previous published papers (Bayat and Ghalandarzadeh, 2018, 2019 and 2020).

\subsection{EFFECT OF $\sigma_{m}^{\prime} A N D D_{r} O N G / G_{\max }-\gamma A N D D-\gamma$ CURVES}

Group 1 of the tests was performed on the all subgroups under isotropic conditions at different values of $D_{r}$ and $\sigma_{m}^{\prime}$. The aim of group 1 testing was to examine the effect of grading characteristics, $D_{r}$ and $\sigma_{m}^{\prime}$ on dynamic properties. In this group of the tests, the WT method was used with a low initial moisture content and consideration of under-compaction of the lower layers during preparation which has the advantage of easy control of void ratio (Ladd, 1987; Maleki and Bayat, 2012). The results show that the effect of $\sigma_{m}^{\prime}$ on the dynamic properties is more significant than the effect of grading characteristics and $D_{r}$. Figure 3(a) shows the effect of $\sigma_{m}^{\prime}$ on $G / G_{\max }$ $-\gamma$ and $D-\gamma$ curves for all subgroups at different $D_{r}$. As expected, $G / G_{\max }$ increased and D decreased as $\sigma_{m}^{\prime}$ increased, especially in the large shear strain region. For example, the effect of $D_{r}$ on $G / G_{\max }-\gamma$ and $D-\gamma$ curves for all subgroups at $\sigma_{m}^{\prime}=600 \mathrm{kPa}$ is shown in Figure 3(b). As expected, $G / G_{\max }$ increased and $D$ decreased as $D_{r}$ increased. More details about effects of $D_{r}$ and $\sigma_{m}^{\prime}$ dynamic properties may be found in Bayat and Ghalandarzadeh (2018). 

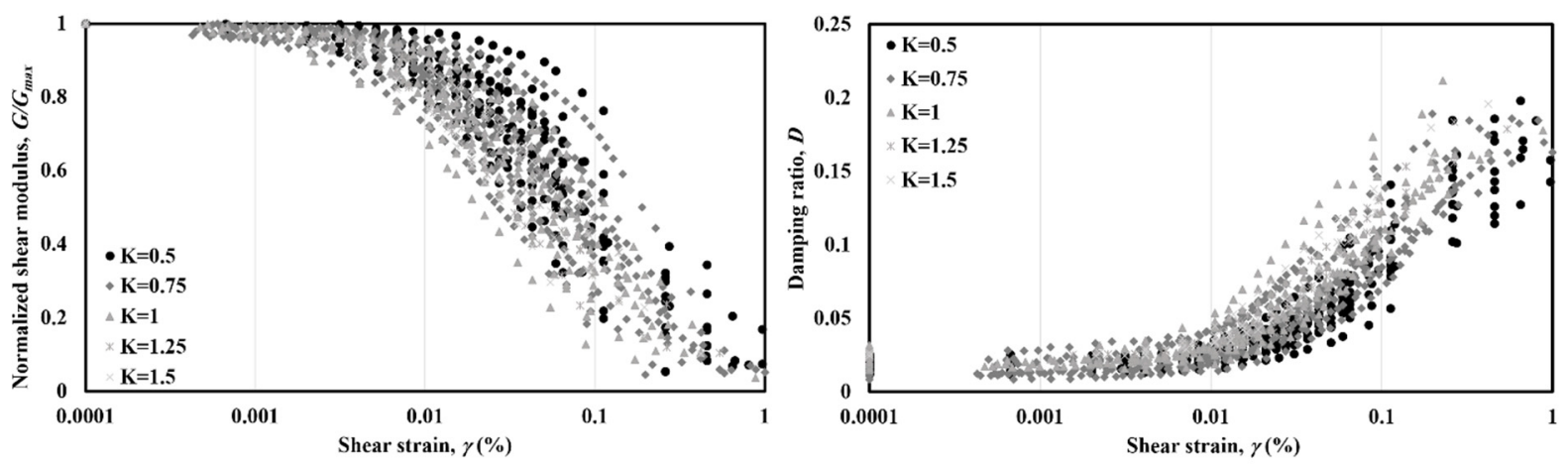

Fig. 4 Variation of $G / G_{\max }$ and $D$ as a function of $\gamma$ in terms of consolidation stress ratio.
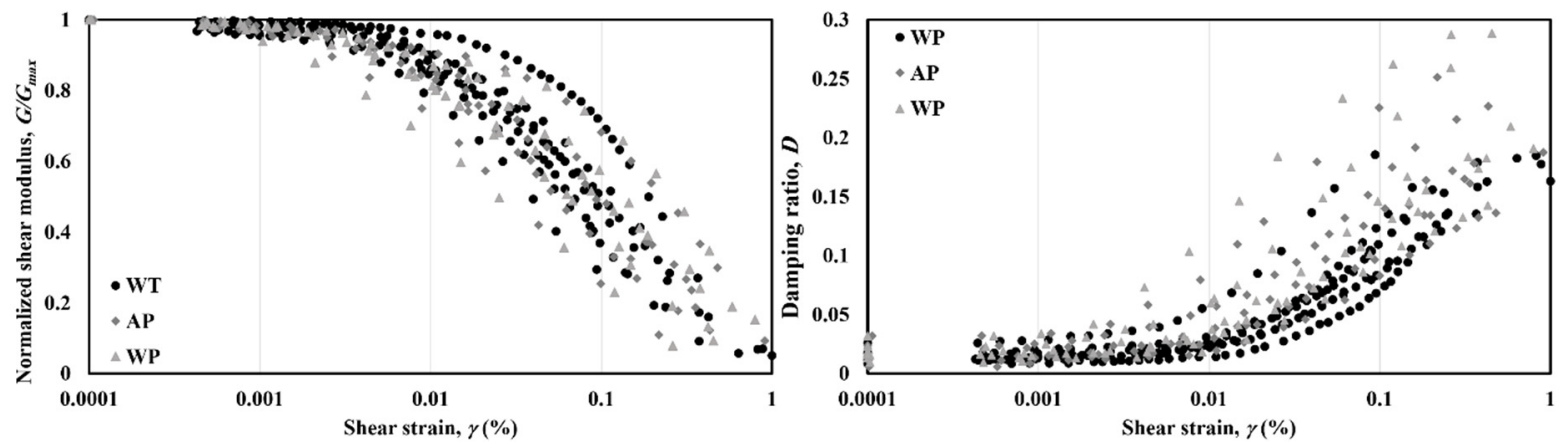

Fig. 5 Variation of $G / G_{\max }$ and $D$ as a function of $\gamma$ in terms of depositional methods.

\subsection{EFFECT OF INDUCED ANISOTROPY ON G/G $\max$ $-\gamma$ AND D $-\gamma$ CURVES}

Group 2 of the tests was performed on the all subgroups under anisotropic conditions at different values of $\sigma_{m}^{\prime}$. All specimens were prepared to a constant $D_{r}$ of about $60 \%$ that refers to the density after the consolidation stage. The aim of group 2 testing was to examine the effect of induced anisotropy on dynamic properties. The consolidation stress ratio $\left(K_{C}=\sigma_{l}^{\prime} / \sigma_{a}^{\prime}\right)$ can be used to describe induced anisotropy, where $\sigma_{l}^{\prime}$ and $\sigma_{a}^{\prime}$ are the lateral and axial effective consolidation stress, respectively. The effect of $K_{C}$ on the $G / G_{\max }-\gamma$ and $D-\gamma$ curves for all subgroups is presented in Figure 4. In general, an increase in $K_{C}$ tends to decrease $G / G_{\max }$ and increased $D$. More details about the effect of $K_{C}$ on the dynamic properties can be found in Bayat and Ghalandarzadeh (2020).

\subsection{EFFECT OF INHERENT ANISOTROPY ON $G / G_{\max }-\gamma$ AND D $-\gamma C U R V E S$}

Group 3 of the tests was performed on saturated specimens of three subgroups $(\mathrm{GC}=0,50$ and 100) by three distinctive methods of specimen preparation, namely, WT, WP and AP. The primary objective of the group 3 of the tests was to evaluate the effect of inherent anisotropy on the dynamic properties of granular soil. The $G / G_{\max }-\gamma$ and $D-\gamma$ curves of the specimens prepared using three methods are presented in Figure 5. The results show that the $G / G_{\max }-\gamma$ curves for the WT specimens goes slightly lower than those of the WS and AP specimens and also the $D-\gamma$ curves for the WT specimens goes slightly lower than those of the AP and WS specimens for a given soil type. More details about the effect of specimen preparation methods on the dynamic properties is also discussed in Bayat and Ghalandarzadeh (2019).

\section{THE PROPOSED MODELS}

The effect of grading characteristics, inherent and induced anisotropy can be added to the general $G_{\max }$ expression as follows:

$$
\mathrm{G}_{\max }=\mathrm{c}_{\mathrm{sp}} \times \mathrm{a}_{1} \times \mathrm{C}_{\mathrm{u}}^{\left[\mathrm{a}_{2}-\frac{\mathrm{D}_{50}}{100}\right]} \times\left(\frac{\sigma_{\mathrm{m}}^{\prime}}{101}\right)^{\mathrm{a}_{3}} \times \frac{\left(\mathrm{a}_{4}-\mathrm{e}\right)^{2}}{\mathrm{a}_{5}+\mathrm{e}} \times\left(\frac{1}{\mathrm{~K}_{\mathrm{C}}}\right)^{\mathrm{a}_{6}}
$$

where $c_{s p}$ is a coefficient reflecting the effect of soil fabric or specimen preparation method. In the current study, $c_{s p}$ for the specimens were prepared by WT, WP and AP are considered equal to 1.2, 1.1 and 1 , respectively. $C_{u}$ and $D_{50}$ are coefficient of uniformity and mean grain-size (in $\mathrm{mm}$ ), respectively. $\sigma_{m}^{\prime}$ is the mean effective confining pressure (in $\mathrm{kPa}$ ) which can be defined as a function of $\sigma_{3}^{\prime}$ and $K_{C}$ $\left(\sigma_{\mathrm{m}}^{\prime}=\left[\sigma_{3}\left(2 \mathrm{~K}_{\mathrm{C}}+1\right)\right] / 3 \mathrm{~K}_{\mathrm{C}}\right)$. Parameters $a_{1}$ to $a_{6}$ are fitting parameters reflecting the effect of particle shape and roughness. As shown in Table $3, a_{1}$ to $a_{6}$ are constant for all subgroups. In the current study, the nonlinear least squares method was used for the identification of the model's parameters. In other words, the parameters were determined in such a way that the sum of the squares of the difference between 
Table 3 The models parameters for soils.

\begin{tabular}{cc}
\hline $\begin{array}{c}\text { Model } \\
\text { parameters }\end{array}$ & $\begin{array}{c}\mathbf{C G}=\mathbf{0} \% \mathbf{G C}=\mathbf{G 0} \%, \mathbf{G C}=\mathbf{5 0} \%, \\
\mathbf{G C}=\mathbf{7 5} \% \text { and } \mathbf{G C}=\mathbf{1 0 0} \% \\
\text { (Current study) }\end{array}$ \\
\hline$a_{1}$ & 195 \\
$a_{2}$ & 0.03 \\
$a_{3}$ & 0.55 \\
$a_{4}$ & 2.97 \\
$a_{5}$ & 14.09 \\
$a_{6}$ & 0.18 \\
$b_{1}$ & 0.05 \\
$b_{2}$ & 0.55 \\
$b_{3}$ & 0.009 \\
$b_{4}$ & 0.03 \\
$c_{1}$ & 1.03 \\
$c_{2}$ & 1.016 \\
$d_{1}$ & 0.03 \\
$d_{2}$ & -0.09 \\
$d_{3}$ & -0.30 \\
$e_{1}$ & 0.10 \\
$e_{2}$ & 0.30 \\
$e_{3}$ & 0.20 \\
\hline
\end{tabular}

a predicted value and the corresponding measured data can be minimized. The parameters were determined by minimizing the respective error using the Solver add- in with Microsoft Excel. $K_{C}$ is the consolidation stress ratio that, as mentioned before, is the lateral to axial effective consolidation stress ratio and $e$ is the void ratio. Figure 6 shows the comparison between the measured and predicted values of the $G_{\max }$ for the all subgroup materials. The predicted values of $G_{\max }$ are mostly within $\pm 25 \%$ of the measured values and $R^{2}$ (correlation coefficient) and RMSE (Root Mean Square Error) are obtained as 0.8623 and 23.4, respectively. As shown in Figure 6, the estimated values of $G_{\max }$ are mostly within $\pm 25 \%$ of the measured values. This validates the feasibility of the presented model to predict $G_{\max }$ under different conditions.

Previous studies indicated that the value of $\gamma_{r}$ (i.e. the shear strain corresponding to $G / G_{\max }=0.5$ ) very significantly affected by the specimen preparation method, the grading characteristics, the mean effective confining pressure and the void ratio and vary less significantly with the induced anisotropy (Bayat and Ghalandarzadeh, 2018, 2019 and 2020; Zhou et al., 2017; Xu et al., 2019). Similar to Eq. (1), the following relationship is assumed for $\gamma_{r}$ :

$\gamma_{\mathrm{r}}=\mathrm{C}_{\mathrm{sp}} \times \mathrm{b}_{1} \times \mathrm{C}_{\mathrm{u}}^{\left[\frac{\left.\mathrm{D}_{\mathrm{s}}\right]}{100}\right]} \times\left(\frac{\sigma_{\mathrm{m}}^{\prime}}{101}\right)^{\mathrm{b}_{2}} \times \frac{\left(\mathrm{b}_{3}-\mathrm{e}\right)^{2}}{\mathrm{~b}_{4}+\mathrm{e}}$

where $b_{1}$ to $b_{4}$ are the fitting parameters which dependent on the shape property and physical parameters of the granular material. Same as before the fitting parameters are constant for all subgroups, which are presented in Table 3.

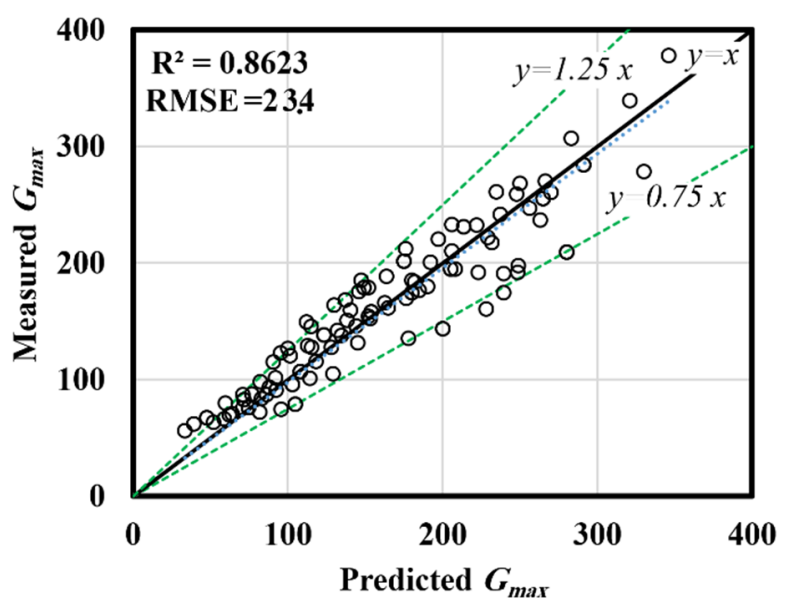

Fig. $6 G_{\max }$-values predicted by Eq. (1) versus measured $G_{\max }$-values in the current study.

In the current study, a relatively simple modified hyperbolic model is used to predict the $G / G_{\max }$ as a function of $\left(\gamma / \gamma_{r}\right)$. After the $\gamma_{r}$ values are calculated based on Eq. (2), the $G / G_{\max }$ of the materials can be predicted using the following equation:

$\frac{G}{G_{\max }}=f\left(\frac{\gamma}{\gamma_{r}}\right)=\frac{1}{\left[1+\left(\frac{\gamma}{\gamma_{r}}\right)^{c_{1}}\right]^{c_{2}}}$

where $c_{1}$ and $c_{2}$ are the fitting parameters which are constant for all the subgroups as shown in Table 3. As shown in Figure 7, the correlation coefficient between the measured and predicted values of $G / G_{\max }$ and RMSE are 0.93 and 0.03 , which validates the feasibility of this model. As can be seen in the results, the estimated values of $G / G_{\max }$ are mostly within $\pm 30 \%$ of the measured values.

Small strain damping ratio, $D_{\min }$, of soil are one of the key input parameters in seismic analysis of the ground. Santamarina and Cascante, (1998) indicated that $D_{\min }$ is not influenced by the void ratio.

The results of the current study indicate that the main factors affecting the $D_{\min }$ are the mean effective confining pressure, void ratio and soil grading characteristics. The following empirical equation is used to estimate the $D_{\min }$ :

$\mathrm{D}_{\min }=\mathrm{d}_{1} \times \mathrm{C}_{\mathrm{u}}^{\mathrm{d}_{2}} \times\left(\frac{\sigma_{\mathrm{m}}^{\prime}}{101}\right)^{\mathrm{d}_{3}}$

where $d_{1}$ to $d_{3}$ are the fitting parameters which are constant for all the subgroups as shown in Table 3. As shown in Figure 8, the proposed equation predicts values relatively well at desired distribution around $y=x$ line and the estimated values of $D_{\min }$ are mostly within $\pm 33 \%$ of the measured values.

In the current study, the $D-D_{\min }$ is also expressed in terms of a polynomial function of $G / G_{\max }$ which has 


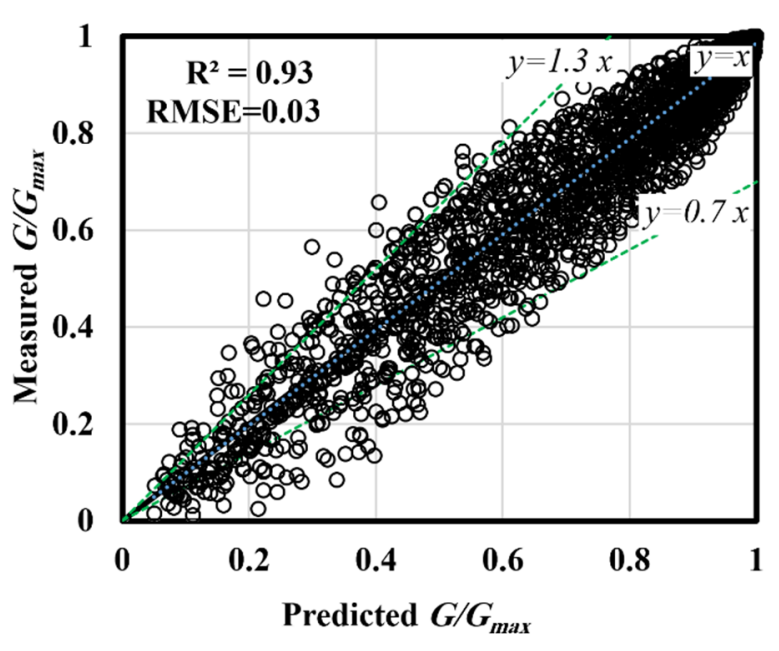

Fig. $7 G / G_{\max }$-values predicted by Eq. (3) versus measured $\mathrm{G} / G_{\max }$-values in the current study.

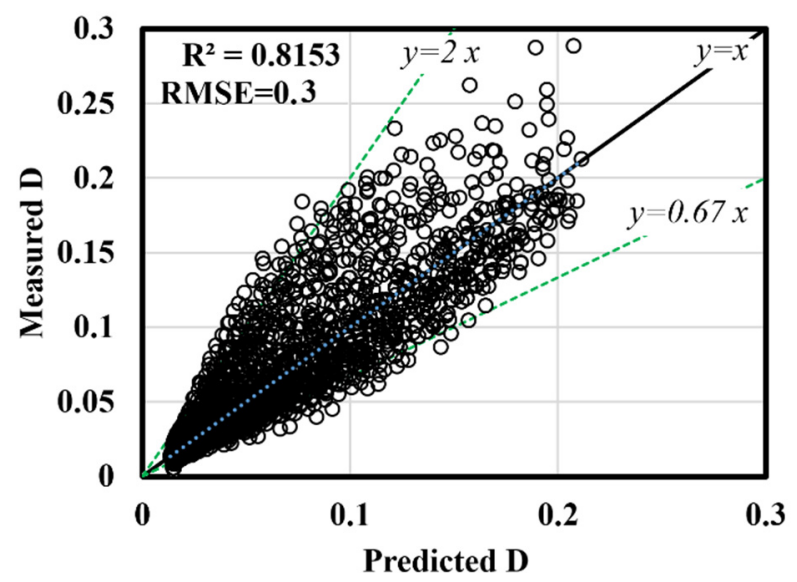

Fig. $9 D$-values predicted by Eq. (5) versus measured $D$-values in the current study.

already been used by Wichtmann and Triantafyllidis (2012) and Zhang et al. (2005):

$\mathrm{D}-\mathrm{D}_{\min }=\mathrm{f}\left(\frac{\mathrm{G}}{\mathrm{G}_{\max }}\right) \rightarrow \mathrm{D}=\mathrm{D}_{\min }+\mathrm{e}_{1}\left(\frac{\mathrm{G}}{\mathrm{G}_{\max }}\right)^{2}+\mathrm{e}_{2}\left(\frac{\mathrm{G}}{\mathrm{G}_{\max }}\right)+\mathrm{e}_{3}$

where $e_{1}$ to $e_{3}$ are fitting parameters in which $e_{1}+e_{2}+e_{3} \approx 0$ so that for very small shear strains $D=D_{\text {min. }} . e_{1}, e_{2}$ and $e_{3}$ values are presented in Table 3 for all the subgroups. It should be noted that the values of $G / G_{\max }$ and $D_{\min }$ in Eq. (5) are calculated from Eqs. (3) and (4), respectively. As shown in Figure 9, the correlation coefficient between the measured and predicted values of $D$ and RMSE are 0.8153 and 0.3 , which indicate that the proposed equation predicts values that are close to the measured ones.

\section{VALIDATION OF THE PROPOSED MODELS WITH PREVIOUS STUDIES}

The data from Chen et al. (2018), Zhou et al. (2017) and Youn et al. (2008) were used to validate

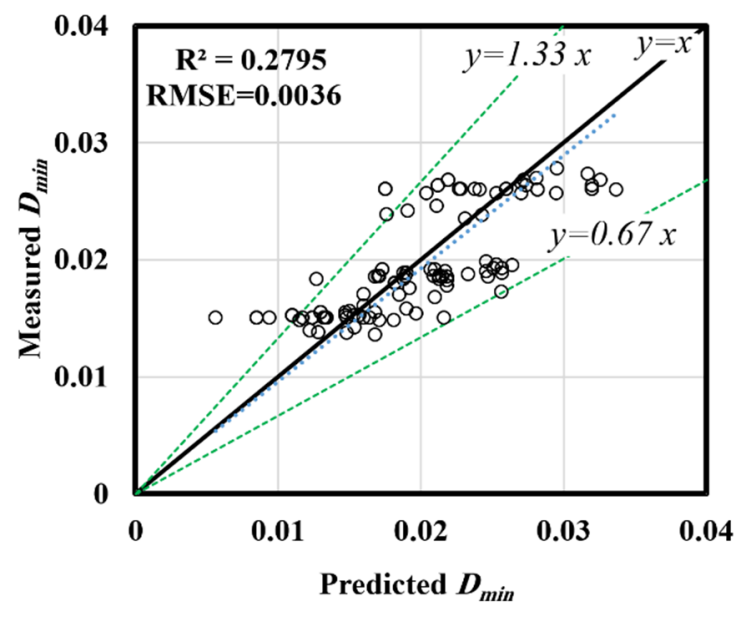

Fig. $8 D_{\min }$-values predicted by Eq. (4) versus measured $D_{\min }$-values in the current study.

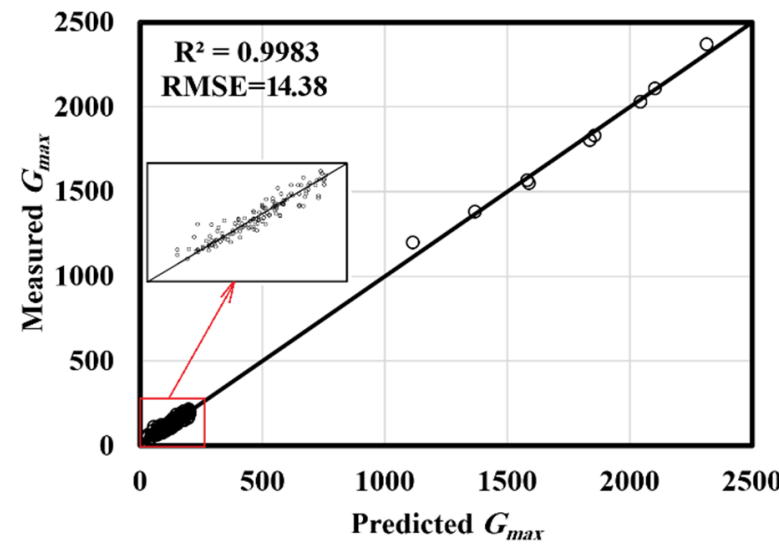

Fig. $10 G_{\max }$-values predicted by Eq. (1) versus measured $G_{\max }$-values in the previous studies.

the ability of the proposed model to predict $G_{\max }$. Table 4 summarizes the sources of data used in validating the model (digitization of the test data was undertaken) and the corresponding values of $\mathrm{R}^{2}$ and RMSE. The best-fit values of the models' parameters for each test group are also listed in Table 4. Figure 10 shows the predicted versus measured values of $G_{\max }$. The values of RMSE and $\mathrm{R}^{2}$ of the model for all data has been illustrated numerically in Figure 10. As shown, the values of RMSE error and $\mathrm{R}^{2}$ between the measured and predicted values is 14.38 and 0.9983 , respectively, which validates the feasibility of the proposed model.

The data from Chen (2017), Zhou et al. (2017), Javdanian and Jafarian (2012), Araei et al. (2010), Youn et al. (2008) and Kokusho (1980) were used to validate the ability of the proposed models to predict the normalized shear modulus and damping ratio of granular soils over a wide shear strain range $(0.0001 \%$ to $10 \%)$. The data were derived from various papers which contains various types of soils tested under 
Table 4 Summarizes the sources of data used in verifying the proposed model of $G_{\max }$ and the corresponding model parameters.

\begin{tabular}{ccccccc}
\hline $\begin{array}{c}\text { Model } \\
\text { parameters }\end{array}$ & $\begin{array}{c}\text { Youn et al. } \\
(\mathbf{2 0 0 8})\end{array}$ & $\begin{array}{c}\text { Youn et al. } \\
(\mathbf{2 0 0 8 )}\end{array}$ & $\begin{array}{c}\text { Zhou et al. } \\
(\mathbf{2 0 1 7})\end{array}$ & $\begin{array}{c}\text { Chen et al. } \\
(\mathbf{2 0 1 8})\end{array}$ & $\begin{array}{c}\text { Chen et al. } \\
(\mathbf{2 0 1 8})\end{array}$ & $\begin{array}{c}\text { Chen et al. } \\
(\mathbf{2 0 1 8})\end{array}$ \\
\hline Materials & Silica sand & $\begin{array}{c}\text { Toyoura } \\
\text { sand }\end{array}$ & HZY-1 & AGS-1 to & AGS-6 to & $\begin{array}{c}\text { SGS-1 to } \\
\text { SGS-7 }\end{array}$ \\
\hline $\boldsymbol{a}_{\boldsymbol{1}}$ & 218 & 183 & 235 & 244 & 240 & 176 \\
$\boldsymbol{a}_{2}$ & 3.30 & 12.30 & 1.49 & 0.46 & 0.14 & 0.28 \\
$\boldsymbol{a}_{\boldsymbol{3}}$ & 0.43 & 0.45 & 0.38 & 0.53 & 0.39 & 0.46 \\
$\boldsymbol{a}_{\boldsymbol{4}}$ & 1.26 & 1.59 & 2.46 & 2.78 & 4.03 & 3.38 \\
$\boldsymbol{a}_{\boldsymbol{5}}$ & 6.47 & 33.55 & 45.75 & 77.74 & 70.97 & 66.80 \\
$\boldsymbol{a}_{\boldsymbol{6}}$ & 1 & 1 & 0.25 & 0.35 & 0.22 & 0.01 \\
\hline $\boldsymbol{R}^{2}$ & 0.99 & 0.99 & 0.98 & 0.81 & 0.88 & 0.88 \\
\hline $\boldsymbol{R M S E}$ & 1.13 & 2.01 & 40.08 & 16.05 & 13.43 & 16.01 \\
\hline
\end{tabular}

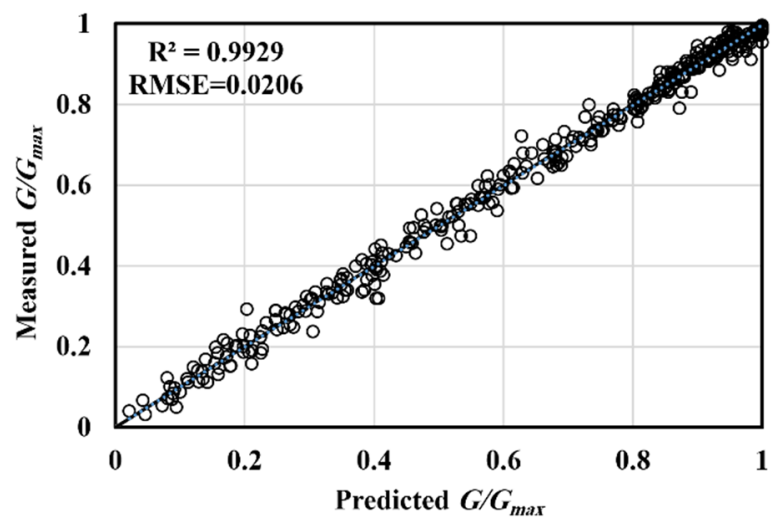

Fig. $11 G / G_{\max }$-values predicted by Eq. (3) versus measured $\mathrm{G} / G_{\max }$-values in the previous studies.

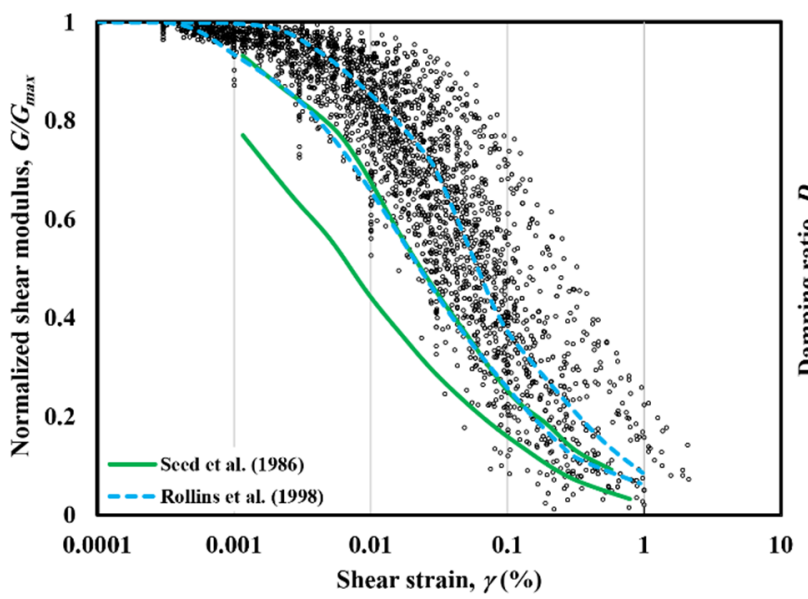

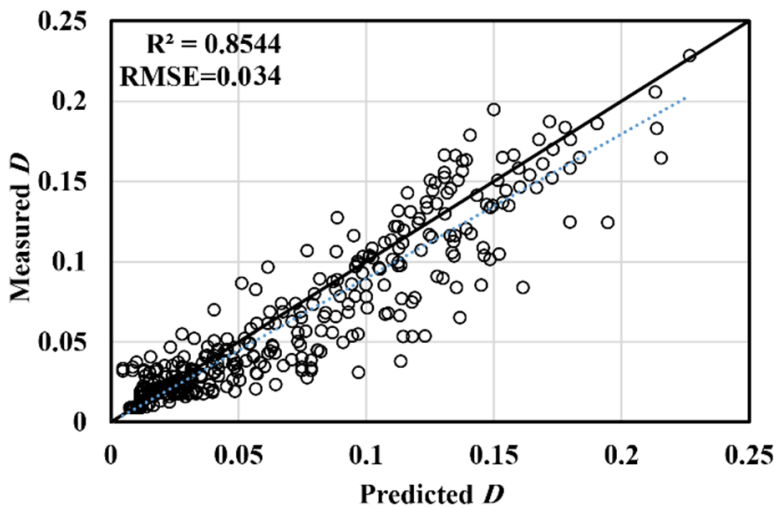

Fig. $12 D$-values predicted by Eq. (4) versus measured $D$-values in the previous studies.

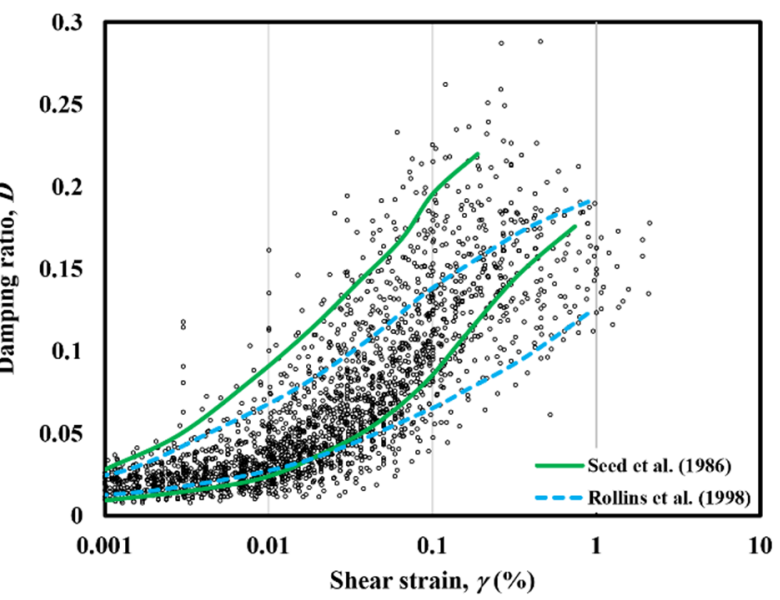

Fig. $13 G / G_{\max }$ and $D-\gamma$ data points along with recommended the lower and upper curves developed by Seed et al. (1986) and Rollins et al. (1998).

a variety of conditions. Table 5 summarizes the sources of data, properties of the specimens and testing conditions that were reported in the original publications. The best-fit values of the models parameters for each test group are also listed in Table 5. Figueres 11 and 12 shows the predicted versus measured values of $G / G_{\max }$ and $D$ for the
34 tests detailed in Table 5, respectively. As shown in Figures 11 and 12, the values of $\mathrm{R}^{2}$ is 0.9929 and 0.8544 for $G / G_{\max }-\gamma$ and $D-\gamma$ curves, respectively, which verifies the feasibility of the proposed models.

All the results in this study and used results of previous studies along with the upper and lower curves of $G / G_{\max }-\gamma$ and $D-\gamma$ as reported by Seed et al. 
Table 5 Summarizes the sources of data used in verifying the proposed models of $\mathrm{G} / G_{\max }$ and $D$ and the corresponding model parameters.

\begin{tabular}{|c|c|c|c|c|c|c|c|c|c|c|c|c|c|c|c|c|c|c|c|}
\hline \multirow[t]{2}{*}{ Publication } & \multirow{2}{*}{$\begin{array}{c}\text { Materials } \\
\text { type }\end{array}$} & \multirow{2}{*}{$\begin{array}{c}\text { Materials } \\
\text { symbol }\end{array}$} & \multicolumn{3}{|c|}{ Soil properties } & \multirow{2}{*}{$\begin{array}{c}\text { Confining } \\
\text { Stress (kPa) }\end{array}$} & \multirow[t]{2}{*}{$K$} & \multicolumn{12}{|c|}{ Models parameters } \\
\hline & & & $D_{50}(\mathrm{~mm})$ & $\overline{C_{u}}$ & $e_{0}$ & & & $b_{1}$ & $b_{2}$ & $b_{3}$ & $\boldsymbol{b}_{4}$ & $c_{1}$ & $c_{2}$ & $d_{1}$ & $d_{2}$ & $d_{3}$ & $e_{1}$ & $e_{2}$ & $e_{3}$ \\
\hline \multirow[t]{2}{*}{$\begin{array}{l}\text { Chen et al. } \\
\text { (2018) }\end{array}$} & $\begin{array}{l}\text { Angular } \\
\text { sand-gravel } \\
\text { mixture }\end{array}$ & AGS 7 & 1.6 & 18.18 & 0.736 & $\begin{array}{l}100 \\
100 \\
100 \\
\end{array}$ & $\begin{array}{l}0.4 \\
0.67 \\
1 \\
\end{array}$ & \multirow[b]{2}{*}{1.39} & \multirow[b]{2}{*}{0.47} & \multirow[b]{2}{*}{0.10} & \multirow[b]{2}{*}{0.10} & \multirow[b]{2}{*}{0.81} & \multirow[b]{2}{*}{2.53} & \multirow[b]{2}{*}{0.001} & \multirow[b]{2}{*}{0.127} & \multirow[b]{2}{*}{0.014} & \multirow[b]{2}{*}{0.01} & \multirow[b]{2}{*}{0.17} & \multirow[b]{2}{*}{0.17} \\
\hline & & AGS 11 & 5.65 & 41.45 & 0.477 & $\begin{array}{l}100 \\
300 \\
500 \\
700 \\
900\end{array}$ & $\begin{array}{l}1 \\
1 \\
1 \\
1 \\
1\end{array}$ & & & & & & & & & & & & \\
\hline \multirow[t]{4}{*}{$\begin{array}{l}\text { Zhou et al. } \\
\text { (2017) }\end{array}$} & $\begin{array}{l}\text { Rockfill } \\
\text { materials }\end{array}$ & $\mathrm{HZY}-1$ & 17.34 & 7.52 & 0.235 & $\begin{array}{l}1000 \\
2000\end{array}$ & $\begin{array}{l}0.67 \\
0.4\end{array}$ & \multirow{4}{*}{0.01} & \multirow{4}{*}{0.31} & \multirow{4}{*}{0.71} & \multirow{4}{*}{1.92} & \multirow{4}{*}{1.05} & \multirow{4}{*}{0.33} & \multirow{4}{*}{0.021} & \multirow{4}{*}{0.001} & \multirow{4}{*}{0.001} & \multirow{4}{*}{0.18} & \multirow{4}{*}{0.36} & \\
\hline & & HZY-2 & 14.2 & 30.25 & 0.195 & $\begin{array}{l}2000 \\
3000 \\
\end{array}$ & $\begin{array}{l}0.4 \\
0.67 \\
\end{array}$ & & & & & & & & & & & & \\
\hline & & HZY-3 & 7.85 & 85.29 & 0.205 & $\begin{array}{l}1000 \\
3000 \\
\end{array}$ & $\begin{array}{l}0.67 \\
0.67 \\
\end{array}$ & & & & & & & & & & & & 0.19 \\
\hline & & $\begin{array}{l}\text { HZY-4 } \\
\text { HZY-5 }\end{array}$ & $\begin{array}{l}17.34 \\
17.34\end{array}$ & $\begin{array}{r}7.52 \\
17.76\end{array}$ & $\begin{array}{l}0.235 \\
0.179\end{array}$ & $\begin{array}{l}1000 \\
2000 \\
2000 \\
3000 \\
\end{array}$ & $\begin{array}{l}0.67 \\
0.4 \\
0.4 \\
0.67 \\
\end{array}$ & & & & & & & & & & & & \\
\hline $\begin{array}{l}\text { Araei et al. } \\
(2010)\end{array}$ & $\begin{array}{l}\text { Rockfill } \\
\text { materials }\end{array}$ & S-3BMES & 10.743 & 652.40 & 0.28 & $\begin{array}{l}700 \\
200\end{array}$ & $\begin{array}{l}1 \\
1\end{array}$ & & & & & & & & & & & & \\
\hline & & S-3AMES & 4.114 & 139.10 & 0.281 & $\begin{array}{l}700 \\
200 \\
\end{array}$ & $\begin{array}{l}1 \\
1 \\
\end{array}$ & & & & & & & & & & & & \\
\hline & & S-SC & 4.100 & 95.53 & 0.227 & $\begin{array}{l}800 \\
200 \\
500\end{array}$ & $\begin{array}{l}1 \\
1 \\
1\end{array}$ & 0.01 & 0.44 & 1.75 & 1.67 & 0.82 & 1.00 & 0.031 & 0.001 & 0.007 & 0.10 & 0.27 & 0.17 \\
\hline & & S-SK & 4.166 & 142.60 & 0.335 & $\begin{array}{l}500 \\
300 \\
\end{array}$ & $\begin{array}{l}1 \\
1 \\
\end{array}$ & & & & & & & & & & & & \\
\hline $\begin{array}{l}\text { Javdanian and } \\
\text { Jafarian } \\
\text { (2012) }\end{array}$ & $\begin{array}{l}\text { Babolsar } \\
\text { sand }\end{array}$ & BSS & 0.35 & 3.43 & 0.53 & $\begin{array}{l}800 \\
400 \\
200\end{array}$ & $\begin{array}{l}1 \\
1 \\
1\end{array}$ & 1.40 & 0.44 & 0.72 & 0.90 & 0.99 & 1.45 & 0.006 & 0.386 & 0.001 & 0.10 & 0.20 & 0.10 \\
\hline $\begin{array}{l}\text { Kokusho } \\
(1980)\end{array}$ & $\begin{array}{l}\text { Toyoura } \\
\text { sand }\end{array}$ & $T$ & 0.198 & 1.34 & 0.643 & $\begin{array}{r}300 \\
200 \\
100 \\
50 \\
20\end{array}$ & $\begin{array}{l}1 \\
1 \\
1 \\
1 \\
1\end{array}$ & 1.38 & 0.49 & 1.28 & 1.40 & 0.72 & 2.00 & 0.011 & 0.572 & 0.054 & 0.15 & 0.42 & 0.27 \\
\hline
\end{tabular}


(1986) and Rollins et al. (1998) are shown in Figure 13. As seen, the measured $G / G_{\max }$ values completely fall above the upper bound trend reported by Seed et al. (1986). The lower curve of Rollins et al. (1998) in the range $\gamma<0.02 \%$ fall below the data; however, the upper range of Rollins et al. (1998) is significantly different compared to the upper range of data. It appears that the upper and lower curves of $D-$ $\gamma$ developed by Seed and Idriss (1986) and Rollins et al. (1998) provide good prediction of damping ratios of granular soils.

\section{CONCLUSIONS}

Previous studies that analyzed dynamic properties of granular soils have most often used different functional forms of models to predict the data which were proposed for specific soil types, loading characteristics, initial soil fabrics and strain ranges. This paper describes the development of universal models to estimate dynamic properties for granular soils from soil grading characteristics, loading conditions and the structure or fabric of the soil. Three models (Eqs. (1), (2) and (4)) have been developed to predict $G_{\max }, D_{\min }$ and $\gamma_{r}$ from a collected database that contains 117 tests. Second, two models (Eqs. (3) and (5)) are presented to estimate $G / G_{\max }$ and $D$ from $G_{\max }, D_{\min }$ and $\gamma_{r}$. The results of the tests indicate that the $G_{\max }$ of granular soils is affected by the grading characteristics, the mean effective confining pressure, the void ratio, the soil fabric, and the consolidation stress ratio. The experimental results exhibit that the $G_{\max }$ increases with increasing mean effective confining pressure and decreases with increasing void ratio or the consolidation stress ratio. As shown in the results, $\gamma_{r}$ can be defined as a function of the grading characteristics, the mean effective confining pressure, the void ratio and the soil fabric which increases with increasing mean effective confining pressure and decreases with increasing void ratio. The tests result show that $\gamma_{r}$ is almost independent of the consolidation stress ratio. Based on the tests results, $D_{\min }$ is defined as a function of grading characteristics and mean effective confining pressure, so that it decreases with increasing uniformity coefficient and mean effective confining pressure. In this work, a relatively simple modified hyperbolic model is used to predict the $G / G_{\max }$ as a function of $\left(\gamma / \gamma_{r}\right)$ and the $D-D_{\min }$ is also expressed in terms of a polynomial function of $G / G_{\max }$. The presented models to estimate $G / G_{\max }-\gamma$ and $D-\gamma$ curves cover a complete range of shear strains and were evaluated against different granular soil types, unlike many of previous models that are valid only for limited ranges of shear strains and provided for a given soil type. The models are validated using experimental data from previous studies for granular soils. The results indicate that the proposed models are capable of evaluating the dynamic properties of granular soils and are sufficiently flexible to be used for any granular soil types. The results also indicate that fitting parameters dependent on shape property and physical parameters of granular material and are independent of grading characteristics. Tables 3 to 5 lists fitting parameters of the proposed models.

\section{REFERENCES}

Amir-Faryar, B., Aggour, M.S. and McCuen, R.H.: 2017, Universal model forms for predicting the shear modulus and material damping of soils. Geomech. Geoengin., 12 , 1, 60-71.

DOI: $10.1080 / 17486025.2016 .1162332$

Anastasiadis, A., Senetakis, K. and Pitilakis, K.: 2011, Small-strain shear modulus and damping ratio of sandrubber and gravel-rubber mixtures. Geotech. Geol. Eng., 30, 2, 363-382. DOI: $10.1007 / \mathrm{s} 10706-011-9473-2$

Araei, A.A. and Ghodrati, A.: 2017, Predictive models for normalized shear modulus and damping ratio of modeled rockfill materials. Acta Geodyn. Geromater., 14, 1, 27-41. DOI: 10.13168/AGG.2016.0025

ASTM D3999: 2013, Standard Test Methods for the Determination of the Modulus and Damping Properties of Soils Using the Cyclic Triaxial Apparatus. DOI: 10.1520/D3999-11E01.1.6

Bayat, M. and Ghalandarzadeh, A.: 2018, Stiffness degradation and damping ratio of sand-gravel mixtures under saturated state. Int. J. Civ. Eng., 16, 10, 1261-1277. DOI: 10.1007/s40999-017-0274-8

Bayat, M. and Ghalandarzadeh, A.: 2019, Influence of depositional method on dynamic properties of granular soil. Int. J. Civ. Eng., 17, 6, 907-920. DOI: $10.1007 / \mathrm{s} 40999-019-00412-7$

Bayat, M. and Ghalandarzadeh, A.: 2020, Modified models for predicting dynamic properties of granular soil under anisotropic consolidation. Int. J. Geomech., 20, 3, 1-15. DOI: 10.1061/(ASCE)GM.1943-5622.0001607

Chen, G., Zhou, Z., Sun, T., Wu, Q., Xu, L., Khoshnevisan, S. and Ling, D.: 2018, Shear modulus and damping ratio of sand-gravel mixtures over a wide strain range. J. Earthq. Eng., 1-34. DOI: $10.1080 / 13632469.2017 .1387200$

Darendeli, M.B.: 2001, Development of a new family of normalized modulus reduction and material damping curves, the Faculty of the Graduate School. Austin, The University of Texas at Austin. PhD. http://hdl.handle.net/2152/10396

Gu, X., Yang, J., Huang, M. and Gao, G.: 2015, Bender element tests in dry and saturated sand: Signal interpretation and result comparison. Soils Found., 55, 5, 951-962. DOI: 10.1016/j.sandf.2015.09.002

Hardin, B.O. and Drnevich, V.P.: 1972, Shear modulus and damping in soils: design equations and curves. J. Soil. Mech. Found. Div ASCE 98 (SM7), 667-692. https://trid.trb.org/view/126413

Jafarian, Y., Haddad, A. and Javdanian, H.: 2014, Predictive model for normalized shear modulus of cohesive soils. Acta Geodyn. Geromater., 14 (1), .27-41. DOI: 10.13168/AGG.2013.0057

Kokusho, T., Hara, T. and Hiraoka, R.: 2004, Undrained shear strength of granular soils with different particle gradations. J. Geotech. Geoenviron. Eng., 130, 6, 621629.

DOI: 10.1061/(ASCE)1090-0241(2004)130:6(621) 
Ladd, R.S.: 1978, Preparing test specimens using undercompaction. Geotech. Test. J., 1, 1, 16-23. DOI: $10.1520 / \mathrm{GTJ} 10364 \mathrm{~J}$

Maleki, M. and Bayat, M.: 2012, Experimental evaluation of mechanical behavior of unsaturated silty sand under constant water content condition. Eng. Geol., 141-142, 45-56. DOI: 10.1016/j.enggeo.2012.04.014

Menq, F.Y.: 2003, Dynamic properties of sandy and gravelly soils. Doctoral dissertation. http://hdl.handle.net/2152/779

Payan, M., Khoshghalb, A., Senetakis, K. and Khalili, N.: 2016, Small-strain stiffness of sand subjected to stress anisotropy. Soil Dynamics and Earthquake Engineering, 88, 143-151. DOI: 10.1016/j.soildyn.2016.06.004

Payan, M., Khoshghalb, A., Senetakis, K. and Khalili, N.: 2016, Small-strain stiffness of sand subjected to stress anisotropy. Soil Dyn. Earthq. Eng., 88, 143-151. DOI: $10.1016 /$ j.soildyn.2016.06.004

Rollins, K.M., Evans, M.D., Diehl, N.B. and Daily III, W.D.: 1998, Shear modulus and damping relationships for gravels. J. Geotech. Geoenviron. Eng., 124, 5, 396-405.

DOI: 10.1061/(ASCE)10900241(1998)124:5(396)

Santamarina, C. and Cascante, G.: 1998, Effect of surface roughness on wave propagation parameters. Geotechnique, 48, 1, 129-136. DOI: $10.1680 /$ geot.1998.48.1.129

Seed, H.B. and Idriss, I.M.: 1970, Soil moduli and damping factors for dynamic response analyses. Rep. 70. Berkeley.: Earthquake Engineering Research Center. https://ci.nii.ac.jp/naid/10022026877/en/

Seed, H.B., Wong, R.T., Idriss, I.M. and Tokimatsu, K.: 1986, Moduli and damping factors for dynamic analyses of cohesionless soils. J. Geotech. Eng., 112, 11, 1016-1032.

DOI: 10.1061/(ASCE)0733-9410(1986)112:11(1016)
Senetakis, K., Anastasiadis, A. and Pitilakis, K.: 2013, Normalized shear modulus reduction and damping ratio curves of quartz sand and rhyolitic crushed rock. Soils Found., 53, 6, 879-893. DOI: $10.1016 / j . s a n d f .2013 .10 .007$

Stokoe II, K.H., Darendeli, M.B., Andrus, R.D. and Brown, L.T.: 1999, Dynamic soil properties.: Laboratory, field and correlation studies. Proc., $2^{\text {nd }}$ Int. Conf. on Earthquake Geotechnical Engineering, 3, Lisbon, Portugal, 811-845.

Wichtmann, T. and Triantafyllidis, T.: 2012, Effect of uniformity coefficient on $\mathrm{G} / \mathrm{G}_{\max }$ and damping ratio of uniform to well-graded quartz sands. J. Geotech. Geoenviron. Eng., 139, 1, 59-72.

DOI: 10.1061/(ASCE)GT.1943-5606.0000735

Wichtmann, T., Hernández, M.N. and Triantafyllidis, T.: 2015 , On the influence of a non-cohesive fines content on small strain stiffness, modulus degradation and damping of quartz sand. Soil Dyn. Earthq. Eng., 69, 103-114. DOI: 10.1016/j.soildyn.2014.10.017

Xenaki, V.C. and Athanasopoulos, G.A.: 2008, Dynamic properties and liquefaction resistance of two soil materials in an earthfill dam-laboratory test results. Soil Dyn. Earthq. Eng. 28, 8, 605-620. DOI: $10.1016 /$ j.soildyn.2007.10.001

Xu, D.S., Liu, H.B., Rui, R. and Gao, Y.: 2019, Cyclic and postcyclic simple shear behavior of binary sand-gravel mixtures with various gravel contents. Soil Dyn. Earthq. Eng., 123, 230-241. DOI: 10.1016/j.soildyn.2019.04.030

Zhang, J., Andrus, R.D. and Juang, C.H.: 2005, Normalized shear modulus and material damping ratio relationships. J. Geotech. Geoenviron. Eng., 131, 4, 453-464. DOI: 10.1061/(ASCE)1090-0241(2005)131:4(453)

Zhou, W., Chen, Y., Ma, G., Yang, L. and Chang, X.: 2017, A modified dynamic shear modulus model for rockfill materials under a wide range of shear strain amplitudes. Soil Dyn. Earthq. Eng., 92, 229-238. DOI: 10.1016/j.soildyn.2016.10.027 